\section{Volcanoes' volatile behaviour}

\section{Jonathan Fink}

THE recent eruptions of Mount Pinatubo in the Philippines and Mount Unzen in Japan have caused local residents, civildefence authorities, politicians, reporters and US military officials to ask three of the most fundamental questions about volcanoes: why do they start erupting, what controls the violence of those eruptions, and when do the eruptions stop being dangerous? A new study by geophysicists Claude Jaupart and Claude Allègre ${ }^{1}$ uses an analysis of gas solubility in molten rock together with observations of several explosive volcanoes to address these questions quantitatively. The paper challenges a prevalent view that the single most important factor controlling the explosiveness of eruptions is the amount of gas dissolved in the source magma body and argues instead that it is the ease with which this gas can escape from the magma as it rises to the surface that influences whether an eruption will be violent. The analysis explains why the appearance of a lava dome in the crater of Mount Pinatubo may be an early sign that explosive activity is coming to a gradual close. However, it also warns that the growth of a dome may be accompanied by violent outbursts of gas-rich magma for weeks, months or years.

The classical view of explosive eruptions may be summarized by a beerbottle analogy. Like a carbonated beverage, magma contains gases that come out of solution under reduced pressure. Depending on the amount of pressure build-up in the bottle before removal of the cap, the frothy liquid may either blow itself apart and shoot out the top, or it may well out quietly and spill down the sides. The 'eruption' stops when the loss of gas brings the internal pressure down to the ambient level. In the geological analogue, explosive eruptions give way to more quiet lava flows and domes after the magma chamber loses a critical amount of gas. According to this interpretation, it is the distribution and quantity of vapour in the source magma body that controls the violence of the eruption and determines when explosive activity will end.

Jaupart and Allègre prefer a pressurecooker model to explain transitions from explosive to passive eruptions. According to their idea, the pressurized vessel consists of both the sub-surface reservoir and the overlying column of magma within the volcano. The pressure in the chamber and the quantity of gas in the magma both control the amount of pressure this molten rock feels. The key element of this model is that the fractured walls of the conduit act like a valve, bleeding off gas from the rising magma and promoting a shift from violent to quiescent eruptions. However, gas can escape only if magma rises slowly enough, and if there is sufficient permeability in the surrounding rocks.

The new calculations show that the rate of gas loss is extremely sensitive, not only to the ascent of velocity of the magma but also to the pressure difference between the chamber and the atmosphere. Consequently, when an eruption reaches the dome-building stage, additional explosions are still likely owing to small fluctuations in pressure. At Mount St Helens in 1980, the major explosive event of 18 May was followed by an outburst a week later, and others in June, July and August. After each of these violent phases, a small dome appeared in the vent, only to be destroyed by the next blast.

The idea that permeability of host rocks can dictate the vigour of an explosive eruption was first promoted by John Eichelberger and his colleagues ${ }^{2,3}$, on the basis of their studies of drill cores from some very young lava flows in California and New Mexico. But, because they lacked the analytical rigour of Jaupart and Allègre, these earlier workers made assumptions that were inconsistent with a range of field observations. Their papers focused on the extrusions that followed the explosive phases, and

claimed that all such domes emerged as highly inflated, permeable foams that collapsed to form dense lava as they travelled from the vent. Yet active domes like Mount St Helens have shown unambiguously that lava can erupt in a dense state that then inflates to bubblerich pumice, rather than vice versa ${ }^{4}$.

A related incorrect assumption of these earlier studies is that lava emerges immediately after the pyroclastic activity ends, so that the gas-loss needed to cause a change in the eruptive behaviour must take place very rapidly. Yet, repose intervals of days, weeks and even decades may separate the end of explosive activity from the first appearance of lava. During such a hiatus, copious amounts of gas can be lost passively through the vent to the atmosphere, thus reducing the need for bleeding of gas into the country rock.

Although these distinctions may seem purely academic, they have important implications for late-stage explosive processes. If all gas must be lost from magma before it can form a lava dome, then there is no possibility that volatiles trapped within an advancing flow may decompress explosively. However, if extrusions can inflate after emergence, they retain the potential to effervesce violently if their

flow fronts collapse. Such behaviour has been documented at many volcanoes ${ }^{5}$, and may have caused the recent loss of life at Unzen. These 'endogenic' explosive processes represent one of the few important effects beyond the scope of Jaupart and Allègre's model.

The principal debate highlighted by this paper may be posed as one of 'nature versus nurture': do magmas completely control their eruptive destiny, or is their behaviour regulated fully by their environment? Jaupart and Allègre's model allows for both types of influence. Pressure variations in the magma body are the ultimate cause of shifts between explosive and extrusive activity, but loss of gas through permeable host-rocks may strongly affect such transitions.

Jonathan Fink is in the Department of Geology, Arizona State University, Tempe, Arizona 85287, USA.

1. Jaupart, C. \& Allègre, C. J. Earth Planet. Sci. Lett. 102 413-429 (1991).

2. Taylor, B. E., Eichelberger, J. C. \& Westrich, H. R. Nature 306, 514-519 (1983)

3. Eichelberger, J. C., Carrigan, C. R., Westrich, H. R. \& Price, R.H. Nature 323, 598-602 (1986).

4. Anderson, S. W. \& Fink, J. H. IAVCEI Proc. in Volcanol. 2 25-46 (1990).

5. Rose, W. J., Pearson, T. \& Bonis, S. Bull. Volcanol. 40, 53-70 (1977) 